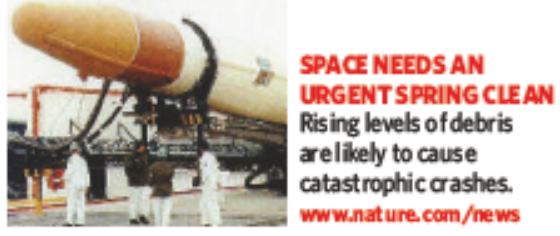

\title{
Bad data fail to halt patents
}

Two patent applications filed by the California Institute of Technology will proceed despite concerns over the accuracy of data they contain, Nature has learned.

The patents were filed on behalf of the institute's president, David Baltimore, and Luk Van Parijs, formerly a professor at the Massachusetts Ins titute of Technology. Van Parijs was considered a rising star in the field of immunology, but was sacked last year for fabricating data in at least one published paper. Several of his papers use duplicate images, but none of his co-authors has been implicated in any misconduct.

Unlike scientific papers, patent applications do not depend ondata buton claims to have conceived a new invention. Inventors often include data, however, to demonstrate the novelty or usefulness of their claims, or to increase the enforceability of the patent once granted.

In the United States, in contrast to many other countries, inventors must sign a declaration affirming that everything in their application is true to the best of their knowledge. The inclusion of false data, even by mistake, could be an infringement of the oath, and thus against the law. Or it could form the basis for questioning the patent later, says Alan Grimaldi, co-chair of the intellectualproperty group at Howrey law firm in Washington DC.

The applications were based on work carried out during Van Parijs's postdoc time in Baltimore's lab; the only other person on them is Lili Yang, a research scientist in the lab. They describe a novel method of gene therapy in which bone-marrow stem cells are infected with a virus to introduce extra genes, then transplanted into a patient where they produce modified immune cells. Depending on the genes inserted, the technique could treat HIV or cancer, the inventors claim.

The research upon which this is based has notbeen questioned. But the patent applications contain at least two instances in which identical images are labelled as coming from different cell populations; three others may also be wrongly identified. When questioned by Nature, Baltimore admittedone of the errors and said he would cor rect it; he is considering the others. He insists, however, that Van Parijs is not responsible. "The patents are fine, and we're proceeding with them," he says.

"Somebody sent in the wrong file. It probably happened in the patent office after we sent them the data."

The status of false data in patents has already come under scrutiny this month. An application on human embryonic stem cells filed by South Korean cloner Woo Suk Hwang of Seoul National University includes data on a cell line discredited by an investigation into his work. His university has said the application will proceed after amendments have been made. If granted, however, some fear it could block patents by other researchers, or that Hwang mightprofit financially from others' work.

The Van Parijs applications may also raise concerns if not corrected. The gene therapy described is a promising area of research, and other work suggests the principle may well be valid. For example, Derek Sant'Angelo at the Memorial Sloan-Kettering Cancer Center in New York has made modified immune cells using a similar approach. In general, the existence of invalid data in patentsintentional or not - would be "a concern" to other inventors, says Sant'Angelo. Eugenie Samuel Reich Erika Check
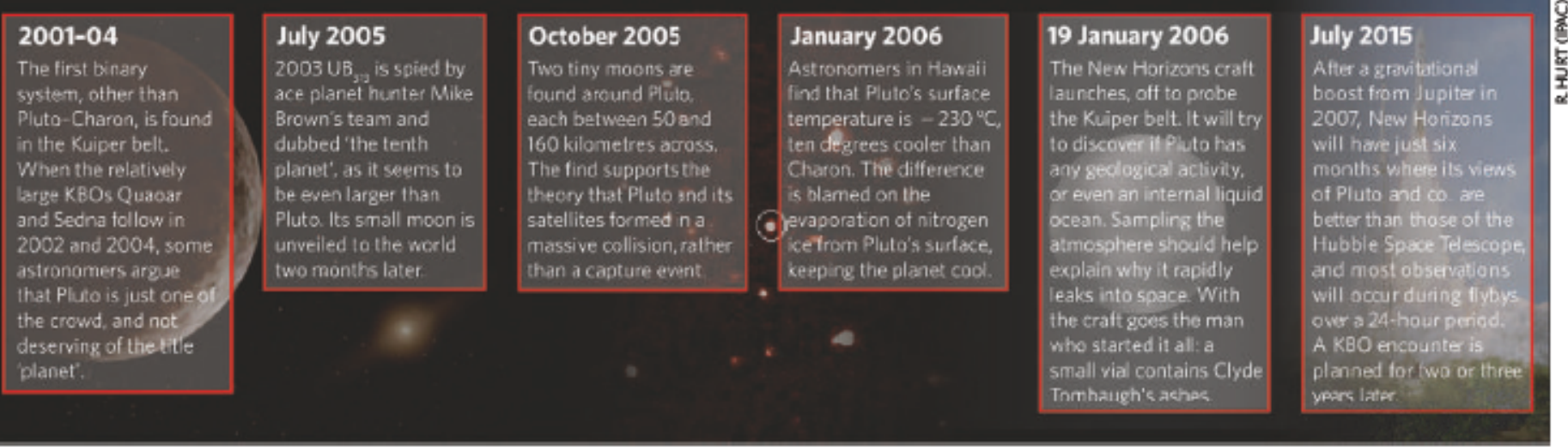